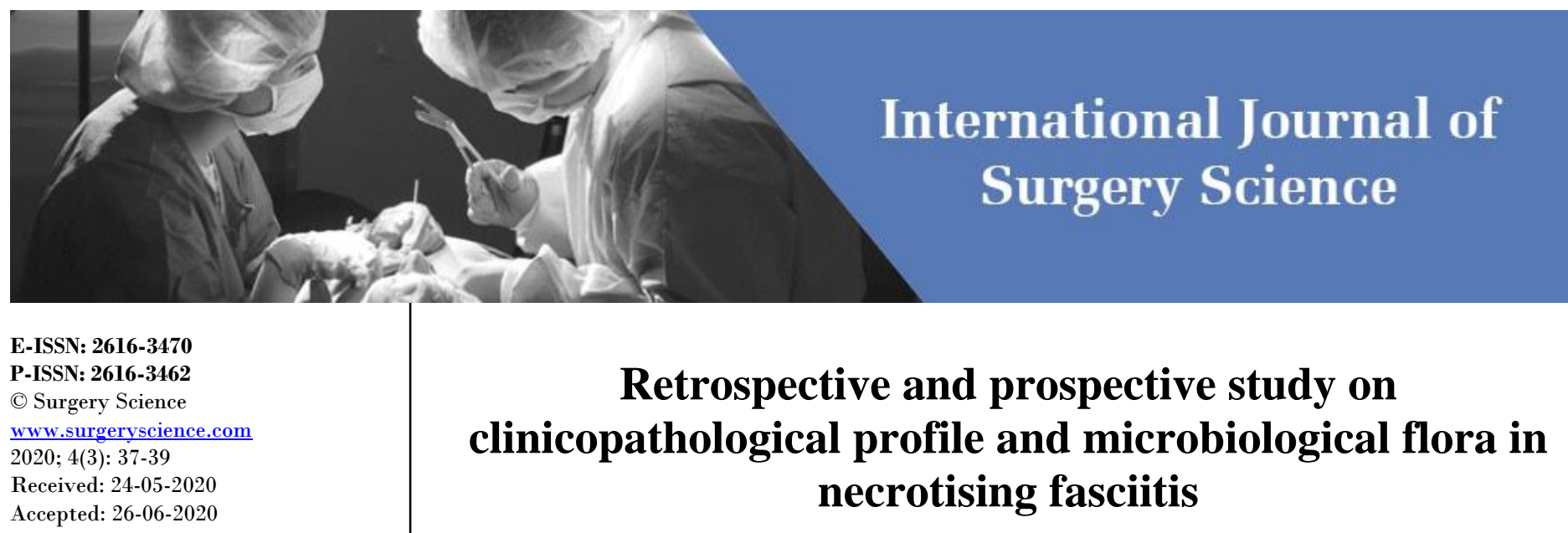

Rakesh Rathore

Senior Resident, Department of General Surgery, Dr. S.N. Medical College, Jodhpur, Rajasthan, India

\section{Ajay Malviya}

Senior Professor, Department of

General Surgery, Dr. S.N. Medical

College, Jodhpur, Rajasthan, India

\section{Govind Sharma}

Resident, Department of General Surgery, Dr. S.N. Medical College, Jodhpur, Rajasthan, India
Corresponding Author: Rakesh Rathore

Senior Resident, Department of General Surgery, Dr. S.N. Medical College, Jodhpur, Rajasthan, India

\section{Rakesh Rathore, Ajay Malviya and Govind Sharma}

DOI: $\underline{\text { https://doi.org/10.33545/surgery.2020.v4.i3a.468 }}$

\section{Abstract}

Necrotizing fasciitis (NF) is potentially lethal bacterial infection characterized by widespread necrosis of the skin, subcutaneous tissue and superficial fascia. Retrospective data was collected from the information available in bed head tickets of patients diagnosed as a case of necrotizing fasciitis. Detailed history and clinical examination was done and recorded. Pus was sent for culture and findings were recorded. Significant observations were: Necrotising fasciitis was seen more in males $(62.22 \%)$ from rural areas $(66.67 \%)$ with mean age at presentation of 47.13 years, trauma being the most common cause $(66.67 \%)$ involving mostly extremities $(72.22 \%)$ with swelling being the most common symptom $(94.45 \%)$. Local tenderness was the most common sign $(92.22 \%)$. Polymicrobial infection was found in all the patients with Staphylococcus aureus as the most common isolate (82.22\%).

Keywords: Retrospective and prospective study necrotizing fasciitis characterized by widespread necrosis

\section{Introduction}

Necrotizing fasciitis is a life-threatening soft-tissue infection that is usually caused by toxinproducing bacteria. It is also called as 'flesh eating disease'. It has got its nickname because it has a high propensity for rapid speed, thus destroying human tissue.

It begins as a low grade cellulitis, followed by rapid onset of fulminant infection in the subcutaneous fascia and accompanying fat necrosis, subcutaneous vessel thrombosis and myonecrosis. Blood supply to the skin is compromised and erythema and edema of the skin progress to bullae and gangrene which is associated with fever, shock and high mortality rate The infection can be associated with severe systemic toxicity and may rapidly progress to death unless promptly recognized and treated.

\section{Methods}

This retrospective and prospective observational study was conducted on in-patient department, cases diagnosed with necrotising fasciitis over a period of three years in a tertiary care hospital. Ethics committee approval was obtained and written informed consent was taken from patients who agreed to participate in the study. Patient clinically diagnosed as necrotizing fasciitis irrespective of age and sex were included in this study.

Detailed history of patients was noted and they were thoroughly examined. Intravenous fluids, wide spectrum antibiotics, analgesics \& inotropes were given as per requirement. Pus was sent for culture and findings recorded.

Categorical data were assessed in the form of absolute numbers and percentages. Quantitative data was assessed by calculating range and measures of central tendency such as mean and standard deviation.

\section{Results}

In our study there were no cases below the age of 21 years while in the age group of 21-40, 41$60,61-80$ there were $57(31.67 \%), 98(54.44 \%)$ and $25(13.89 \%)$ patients respectively. (Table 1). The mean age of presentation was 47.13 years.

Out of 180 patients $112(62.22 \%$ ) were males and 68(37.78\%) were females (Table 2) with a male female ratio of $1.6: 1$. 
In our study most of the patients were from rural areas, 120 $(66.67 \%)$ as compared to urban $60(33.33 \%)$ \& rural urban ratio was 2:1. (Table 3) Patients from rural areas are prone to trauma and subsequent infection due to their habit of walking bare foot. In our study the most common cause of necrotizing fasciitis was trauma seen in $120(66.67 \%)$ patients followed by unknown bite in $40(22.22 \%)$ whereas no cause was found in $20(11.12 \%)$ patients. (Table 4)

In the present study the most common symptom observed at the affected site was swelling found in 170 (94.45\%) patients followed by pain in $152(84.44 \%)$ and redness in $120(66.67 \%)$ patients. Local tenderness was present in $166(92.22 \%)$ patients followed by bullae $42(23.33 \%$ ) and crepitus $15(8.34 \%)$ patients. (Table 5).

In the present study, the most commonly affected site were extremities seen in $130(72.22 \%)$ patients followed by perineum in $40(22.22 \%)$ \& abdomen in $22(12.23 \%)$ patients. (Table 6).

In our study polymicrobial infection was present in all patients. Staphylococcus aureus, Streptococcus pyogenes, Pseudomonas aeuroginosa were isolated in 56 (31.11\%) patients. Staphylococcus aureus, Pseudomonas aeuroginosa, Klebsiella species were grown on culture in $48(26.67 \%)$ patients whereas Streptococcus pyogenes, Pseudomonas aeuroginosa, Klebsiella species were isolated in $31(17.22 \%)$ patients. Staphylococcus aureus, KlebsiellasSpecies, E. coli were the organisms grown on culture in $26(14.44 \%)$ patients, Staphylococcus aureus, E. coli in $18(10.00 \%)$ whereas Pseudomonas aeuroginosa, Klebsiella species only in $1(0.56 \%)$ patient. (Table 7$)$.

Our study found that necrotizing fasciitis infection was polymicrobial in nature and most common bacteria isolated in pus culture of wound was Staphylococcus aureus 148 (82.22\%) while Pseudomonas aeuroginosa was found in $136(75.55 \%)$ followed by Klebsiella species in 106(58.89\%) Streptococcus pyogenes in $88(48.89 \%)$ and E. coli in 44 (24.44\%) patients. (Table 8).

Table 1: Age wise distribution of patients in the study

\begin{tabular}{|c|c|c|}
\hline Age (yrs.)* & No. of patients & Percentage \\
\hline $21-40$ & 57 & 31.67 \\
\hline $41-60$ & 98 & 54.44 \\
\hline $61-80$ & 25 & 13.89 \\
\hline Total & 180 & 100.00 \\
\hline
\end{tabular}

*no cases below the age of 21 years.

Table 2: Sex wise distribution of patients in the study

\begin{tabular}{|c|c|c|}
\hline Sex & No. of patients & Percentage \\
\hline Male & 112 & 62.22 \\
\hline Female & 68 & 37.78 \\
\hline Total & 180 & 100.00 \\
\hline
\end{tabular}

Table 3: Distribution of patients according to locality

\begin{tabular}{|c|c|c|}
\hline Locality & No. of patients & Percentage \\
\hline Rural & 120 & 66.67 \\
\hline Urban & 60 & 33.33 \\
\hline Total & 180 & 100 \\
\hline
\end{tabular}

Table 5: Clinical presentation of necrotizing fasciitis

\begin{tabular}{|c|c|c|c|}
\hline \multicolumn{2}{|c|}{ Clinical presentation } & No of patients & Percentage \\
\hline \multirow{3}{*}{ a) Symptoms } & Swelling* $^{*}$ & 170 & 94.45 \\
\cline { 2 - 4 } & Pain $^{*}$ & 152 & 84.44 \\
\cline { 2 - 4 } & Redness $^{*}$ & 120 & 66.67 \\
\hline
\end{tabular}

\footnotetext{
*at affected site
}

\begin{tabular}{|c|c|c|c|}
\hline \multicolumn{2}{|c|}{ Clinical presentation } & No of patients & Percentage \\
\hline \multirow{3}{*}{ b) Signs } & Local tenderness & 166 & 92.22 \\
\cline { 2 - 4 } & Bullae & 42 & 23.33 \\
\cline { 2 - 4 } & Crepitus & 15 & 8.34 \\
\hline
\end{tabular}

Table 6: Site of necrotizing fasciitis

\begin{tabular}{|c|c|c|}
\hline Site & No. of patients & Percentage \\
\hline Extremities & 130 & 72.22 \\
\hline Perineum & 40 & 22.22 \\
\hline Abdomen & 22 & 12.23 \\
\hline
\end{tabular}

Table 7: Microbiological flora in pus culture for aerobic organisms

\begin{tabular}{|c|c|c|c|}
\hline Group & Type of organism & $\begin{array}{c}\text { No. of } \\
\text { patients }\end{array}$ & Percentage \\
\hline 1 & $\begin{array}{c}\text { Staphylococcus } \\
\text { Aureus,Streptococcus } \\
\text { Pyogenes, } \\
\text { Pseudomonas Aeuroginosa }\end{array}$ & 56 & 31.11 \\
\hline 2 & $\begin{array}{c}\text { Staphylococcus Aureus, } \\
\text { Pseudomonas Aeuroginosa, } \\
\text { Klebsiella Species }\end{array}$ & 48 & 26.67 \\
\hline 3 & $\begin{array}{c}\text { Streptococcus Pyogenes, } \\
\text { Pseudomonas Aeuroginosa, } \\
\text { Klebsiella Species }\end{array}$ & 31 & 17.22 \\
\hline 4 & $\begin{array}{c}\text { Staphylococcus Aureus, } \\
\text { E. coli, Klebsiella Species } \\
\text { Staphylococcus Aureus, } \\
\text { E. coli }\end{array}$ & 26 & 14.44 \\
\hline 6 & $\begin{array}{c}\text { Pseudomonas Aeuroginosa, } \\
\text { Klebsiella Species }\end{array}$ & 1 & 10.00 \\
\hline Total & r & 180 & 100 \\
\hline
\end{tabular}

Table 8: Distribution of aerobic organism in pus culture

\begin{tabular}{|c|c|c|}
\hline Type of organism & No. of patients & Percentage \\
\hline Staphylococcus Aureus & 148 & 82.22 \\
\hline Pseudomonas Aeuroginosa, & 136 & 75.55 \\
\hline Klebsiella Species & 106 & 58.89 \\
\hline Streptococcus Pyogenes & 88 & 48.89 \\
\hline E. Coli & 44 & 24.44 \\
\hline
\end{tabular}

\section{Discussion}

Present study comprises a review of 180 patients with necrotising fasciitis, admitted in various surgical wards of a tertiary care hospital over a period of three years.

In our study there were no cases below the age of 21 years while in the age group of $21-40,41-60,61-80$ there were $57(31.67 \%)$, $98(54.44 \%)$ and $25(13.89 \%)$ patients respectively. The mean age of presentation was 47.13 years. These results are similar to the study conducted by Martin et al. (2008) ${ }^{[1]}$ who observed that the patients age range was from 19 to 75 years with a mean of 41.6 years. Similar studies by Yuag et al. (2005) ${ }^{[2]}$ and Nissar Sheikh (2010) [3] observed the mean age of 53.4 and 48.6 years respectively.

Out of 180 patients $112(62.22 \%)$ were males and 68(37.78\%) were females with a male female ratio of 1.6:1. The findings of study are similar to that of Yuag et al. (2005) ${ }^{[2]}$ who observed a ratio of 2.5:1. Similarly Nissar Sheikh (2010) ${ }^{[3]}$ observed male female ratio of 3:1 in his study whereas Wong et al. (2003) ${ }^{[4]}$ found no such difference.

In our study most of the patients were from rural areas, $120(66.67 \%)$ as compared to urban $60(33.33 \%)$ \& rural urban ratio was $2: 1$. Patients from rural areas are more prone to trauma and subsequent infection due to their habit of walking bare foot. In our study the most common cause of necrotizing fasciitis was trauma seen in $120(66.67 \%)$ patients followed by unknown bite 
in $40(22.22 \%)$ whereas no cause was found in $20(11.12 \%)$ patients. Our study is similar to that of Anaya et al. ${ }^{[5]}$ who observed that $46 \%$ and $18 \%$ cases were due to trauma and of spontaneous onset respectively. Fournier JA in $1884^{[6]}$ showed that necrotizing fasciitis of the perineum can arise spontaneously or may develop from a perineal abscess, bartholin gland infection, scrotal infections and genitourinary procedures.

In the present study the most common symptom observed at the affected site was swelling found in 170 (94.45\%) patients followed by pain in $152(84.44 \%)$ and redness in $120(66.67 \%)$ patients. Local tenderness was the most common sign in 166 $(92.22 \%)$ followed by bullae in $42(23.33 \%)$ and crepitus in $15(8.33 \%)$ patients. Similarly, Sing et al. [7] in his study observed swelling in $99 \%$ followed by pain in $91 \%$ and redness in $72 \%$ patients whereas he noted local tenderness in $91 \%$ followed by bullae and crepitus in $15 \%$ patients each. Most common sign noted was local tenderness in $72.9 \%$ followed by bullae in $15 \%$ and crepitus in $36 \%$ of the patients.

In the present study, the most commonly affected site was extremities seen in $130(72.22 \%)$ cases followed by perineum in $40(22.22 \%) \&$ abdomen in 22(12.23\%). In 12(6.67\%) patients both abdomen and perineum were involved. The findings of the study are similar to that of Sing et al. [7] who observed extremities involvement in $76 \%$, perineum in 28 and abdomen in $36 \%$ of the patients.

In our study polymicrobial infection was present in all patients. Staphylococcus aureus, Streptococcus pyogenes, Pseudomonas aeuroginosa were isolated in 56 (31.11\%) patients. Staphylococcus aureus, Pseudomonas aeuroginosa, Klebsiella species were grown on culture in $48(26.67 \%)$ patients whereas Streptococcus pyogenes, Pseudomonas aeuroginosa, Klebsiella species were isolated in $31(17.22 \%)$ patients. Staphylococcus aureus, Klebsiella species, E. coli were the organisms grown on culture in $26(14.44 \%)$ patients, Staphylococcus aureus, E. coli in $18(10.00 \%)$ whereas Pseudomonas aeuroginosa, Klebsiella species only in $1(0.56 \%)$ patient. McHenry CR (1995) ${ }^{[8]}$, Wong CH (2003) ${ }^{[9]}$, Childers BJ et al. (2002) ${ }^{[10]}$ in their study stated that $55 \%$ to $75 \%$ of the infections were polymicrobial in nature and most common organisms isolated were E.coli and Proteus.

Our study found that necrotizing fasciitis infection was polymicrobial in nature and most common bacteria isolated in pus culture of wound was Staphylococcus aureus 148(82.22\%) while Pseudomonas aeuroginosa was found in 136(75.55\%) followed by Klebsiella species in 106(58.89\%) Streptococcus pyogenes in $88(48.89 \%)$ and E. coli in $44(24.44 \%)$ patients. The findings of study are similar to that of Yuag et al. (2005) ${ }^{[2]}$ who had isolated Staph aureus as the most common organism in $78 \%$ followed by Streptococcus in $43 \%$ patients. Brook and Frazier (1995) ${ }^{[11]}$ concluded that Staph aureus was the most common aerobic organism in $67.3 \%$ followed by Streptococci in $23 \%$ and E. coli in $14.8 \%$ in their patients.

\section{Conclusion}

Necrotising fasciitis is a potentially lethal bacterial infection preponderant in males within the age group of 40-60 years in rural areas perhaps due to increase incidence of trauma, presenting with swelling, pain and redness and is mostly due to polymicrobial infection, Staphylococcus aureus being the most common organism involved.

\section{References}

1. Martin, Deborh A et al. "Necrotizing Fasciitis with No Mortality or Limb Loss." American Surgeon. 2008; 32:809812.
2. Yuag-Meng Liu, Chih-Yu Chi, Mao-Wang Ho et al. Microbiology and factors affecting mortality in necrotizing fasciitis, J Microbiol Immunol Infect. 2005; 38:430-435.

3. Nissar Shaikh, Firdous Ummunissa, Yolande Hanssen et al. Hospital epidemiology of emergent cervical necrotizing fasciitis. Journal of Emergencies, Trauma, and Shock. 2010; 3(2):123-125.

4. Wong $\mathrm{CH}$, Chang $\mathrm{HC}$, Pasupathy $\mathrm{S}$ et al. Necrotizing fasciitis: clinical presentation, microbiology, and determinants of mortality. 2003; 85A(8):1454-1460.

5. Anaya DA, McMahon K, Nathens AB et al. Predictors of mortality and limb loss in NSTI. Arch Surg, 2005, 151-157.

6. Fournier JA. Etude clinique de la gangrene foudroyante de la verge. Semaine Med. 1884; 4:69.

7. Singh G, Sinha S, Adhikary S, Babu K. Necrotizing infection of soft tissue- a clinical profile. EurJ Surg. 2002; 168:366-371.

8. McHenry CR, Piotrowski JJ, Petrinic D et al. Determinants of mortality in necrotizing soft tissue infections. Ann Surg. 1995; 221:558-563.

9. Wong $\mathrm{CH}$, Chang $\mathrm{HC}$, Pasupathy $\mathrm{S}$ et al. Necrotizing fasciitis: clinical presentation, microbiology, and determinants of mortality. 2003; 85A(8):1454-1460.

10. Childers BJ, Potyondy LD, Nachreiner R et al. Necrotizing Fasciitis: a fourteen-year retrospective study of 163 consecutive patients.Am Surgeon. 2002; 68:109-116.

11. Brook I, Frazier EH. Clinical and microbiological features of necrotizing fasciitis. J Clin Microbiol. 1995; 33:23822387. 